\title{
Social Support, Work-Family Enrichment and Life Satisfaction among Married Nurses in Health Service
}

\author{
Wan Edura Wan Rashid, Mohamad Sahari Nordin, Azura Omar, and Izhairi Ismail
}

\begin{abstract}
The objectives of this research are i) to examine the psychometric properties of the constructs of social-support, work-family enrichment and life satisfaction, ii) to validate the hypothesized interrelationships among the constructs of social support, work-family enrichment and life satisfaction among nurses of public hospitals in Malaysia and iii) to examine the likely mediation effect of work-family enrichment on support-satisfaction relationship. Survey questionnaire was administered to 689 married nurses of public hospitals in Malaysia. A full structural modeling testing was used in SEM with AMOS 17 data-fitting program, supported the hypothesized relationship. The results substantiated the psychometric adequacy of the measure and produced a good-fitting life satisfaction model among nurses.
\end{abstract}

Index Terms-satisfaction, social-support and work-family enrichment.

\section{INTRODUCTION}

Work and family signify two important components in the lives of most people [1, 2]. As such, it is not all surprising that work and family roles can produce significant impact on life satisfaction [3]. In fact, managing the intersection between work and family is one of the critical issues for both management practitioners and academics [4]. In recent years, balancing work and family has become a more prominent issue given the following changes in the lives of men and women: 1) both men and women juggling work and family roles simultaneously; 2) the existence of dual-income families, single parents and a growing number of women in the workforce; 3 ) the attitudes and values of men and women towards other aspects of life such as religion, leisure and the general quality of life [5].

Organizations must give serious attention to the relationships between work and family roles and other related constructs including individual satisfaction. Helping employees strike a balance between work and family maybe the solutions for organizations to attract and retain capable

Manuscript received July 7, 2011; revised July 20, 2011

Wan Edura Wan Rashid is with the Faculty of Office Management and Technology, Universiti Teknologi MARA Kampus Puncak Alam, 42300, Bandar Puncak Alam (e-mail: wanedura@yahoo.com.).

Mohamad Sahari Nordin is with Research Management Centre, International Islamic University Malaysia, Gombak 53100, Kuala Lumpur. (e-mail: msahari@iium.edu.my).

Azura Omar is with the Kulliyyah of Economics and Management Sciences, International Islamic University Malaysia, Gombak 53100, Kuala Lumpur. (e-mail: azura_omar@iium.edu.my).

Izhairi Ismail is with the Kulliyyah of Economics and Management Sciences, International Islamic University Malaysia, Gombak 53100, Kuala Lumpur. (e-mail: izhairi@iium.edu.my). employees. Understanding the work-family balance is crucial in enabling employees to experience satisfaction in life. Critically, it can be argued that satisfaction in life will enhanced job satisfaction and that job satisfaction leads to better and improved individual and organizational performances. As such, it is in the best interest of the organizations to execute practices that allow their employees to perform at work as well as function meaningfully in their homes.

There are three objectives of this study; i) to examine the psychometric properties of social-support, work-family enrichment and life satisfaction, ii) to validate the hypothesized interrelationships among the constructs of social support, work-family enrichment and life satisfaction among nurses of public hospitals in Malaysia and iii) to examine the likely mediation effect of work-family enrichment on support-satisfaction relationship.

\section{THEORETICAL UnDERPINING OF THE STUDY}

The intersection of work and family can be approached in two ways: 1) using work-family conflict theory and 2) using work-family enrichment theory. Based on work-family enrichment theory [6] that promotes the positive effects of juggling work and family roles [7-9], this study examines three constructs that have a causal link to one another. They are social support, work-family enrichment and satisfaction (Figure 1).

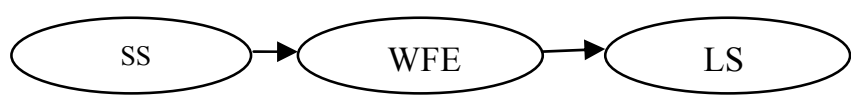

Fig. 1.Hypothesized model

(SS)- Social Support, (WFE) -Work-Family Enrichment and ( LS) - Life Satisfaction.

\section{A. Social Support}

In this study, social support is divided into two categories, work domain (supervisors) and non-work domain (spouse and family members). Social support has been identified as an important resource that can produce effective coping in the event of work and family conflict, and is regarded as a core factor in enhancing the physical and mental health of employees [10]-[14]. The phenomenon of social support is paramount for nurses and patients. If nurses have adequate support, they may experience less stressed, have better morale and able to provide better quality of service to patients. Noraini [2] highlighted that social support can directly enhance well-being, lessen the impact of stress on well-being and prevent psychological distress following a stressful 
experience. Besides, Gelsema et al. [15] found that the strongest predictors of job satisfaction in hospital nurses were support from a supervisor, positive rewards, and perceived control over workload. In terms of family support, Chen and Lin [16] reported that support from the family can increase women's sense of satisfaction towards their family. Therefore, if the nurses receive support from non-work domain, it can help to increase family satisfaction.

\section{B. Work-Family Enrichment}

Theory of work-family enrichment provides a clear picture of positive outcomes of combining work and family roles. While there maybe other possible explanation for work-family enrichment, the study focuses on the impact of social capital resources. According to Greenhaus and Powel [6], social capital resources generated from one role (work) can improve the quality of life in the other role (family) or vice versa. In this study, it is proposed that social capital resources are achieved when a nurse received social support at home or at work. For instance, if Maria receives the support she needs from her spouse, she may be able to better manage an unpleasant situation at the work place. From this example, support that comes from the personal role can help to enhance the quality of life in the work role. A recent study by Hennessy [17] involving 161 employed women has shown this to be true. The findings revealed that support has a significant relationship with work-family enrichment.

\section{Life Satisfaction}

Life satisfaction outcomes in this study are divided into three parts: 1) job satisfaction, 2) family satisfaction and 3) well-being satisfaction. Based on a work-family enrichment theory, if a person's work role is enhancing his/her family role, it seems logical to hypothesize that this may be related to an increase in satisfaction in one's family role. Similarly, if a person's family role is enhancing his/her work role, an increase in work satisfaction could be possible. Henessey [17] provided support to this claim, indicating that work-family enrichment has a positive relationship with both work and family satisfaction. Specifically, the author reported that women with higher levels of work-family enrichment are more likely to experience higher levels of work and family satisfaction. Grzywacz [18] proposed that work and family enrichment may help to strengthen social relationships, thereby providing a buffer against negative events which will lead to improved health outcomes. However, no empirical evidence exists with regards to the relationship between work-family enrichment and well-being satisfaction.

\section{Methodology}

A total of 710 questionnaires were distributed to married female nurses in public hospitals in Malaysia. Although, the response rate was $100 \%, 21$ questionnaires were later discarded because of missing data. Therefore, the effective response rate was approximately $97 \%$. The sample size was deemed adequate for the application of structural equation modeling (SEM) to address the research objectives. The majority of the respondents $(72.6 \%)$ were Malay with diploma holders and above 40 years old. From the survey, it revealed that $36 \%$ of the respondents have worked as nurses between 4 to 10 years.

This study adapted the measures used in previous studies. The measures of social support were adapted from the Sarason, Sarason, Shearin and Pierce's [19] shortened version of the Social Support Questionnaire. The Work-to-Family Enrichment and Family-to-Work Enrichment were assessed using two scales by Carlson et al. [20]. The measure of family satisfaction was adapted using a modified 5-item version of Brayfied and Rothe's [21] Job Satisfaction Scale. In this modified version, the word "work" has been replaced with the term "family life". Items for job satisfaction were assessed using the 3-item General Job Satisfaction subscale, which is part of the Job Diagnostic Survey (JDS) developed by Hackman \& Oldham [22]. The Well Being Satisfaction, was adapted from the Overall Life Satisfaction scale developed by Quinn and Staines [23]. All items were measured using a six-point Likert-type scale (ranging from $1=$ strongly disagree to $6=$ strongly agree). Later, the questionnaire was rigorously pilot tested on 100 respondents before the main data collection was performed. This pilot study was very important in ensuring more reliable data collected during the major survey with establishment of content validity. The respondents were invited to comments on the questionnaires and thus, their constructive comments provided a basis for refinement to the construct measures.

Using AMOS (version 17) the maximum likelihood estimation, the study tested the adequacy of the hypothesized models, which include several measurement models and a structural model. The hypothesized models were empirically tested using a two-step structural equation modeling (SEM) approach. The measurement models were first estimated using confirmatory factor analysis (CFA); then the good-fit of full structural model was examined.

\section{RESULT}

The first measurement model (Figure 2) comprised of two correlated constructs of social support (supervisor and family support). Each of these constructs was measured by more than three items and each item was assumed to load only on its respective dimension. The two factors, namely the supervisor support and family support were expected to load on the social support.

Using the maximum likelihood estimation procedure of the confirmatory factor analysis, the validity of this measurement model was tested first. The results indicated that all indicators falling on its posited underlying factor were statistically significant with all critical ratios (t-values) were above \pm 1.96 at 0.05 level respectively. The overall fit of the model was 187.420 , the relative Chi-square $=3.53$; RMSEA $=.061$, $\mathrm{NFI}=.965$ and $\mathrm{CFI}=.975$. In other words, the measurement of social support did generate the observed covariance matrix; there was no evidence that the measurement model is incorrect. In addition, the direction and magnitude of factor loadings were substantial and statistically significant, and the model was free from offending estimates. Table 1 reported the detail of measurement of the variables of the hypothesized model. 
TABLE 1. MEASUREMENT OF THE VARIABLES OF THE HyPOTHESIZED MODEL

\begin{tabular}{|c|c|c|c|c|c|}
\hline Construct & Item & Measure & Mean & SD & Alpha \\
\hline & B3 & Is supportive to my efforts to combine work and family. & 3.33 & 1.472 & .901 \\
\hline \multirow{5}{*}{$\begin{array}{l}\text { Supervisor } \\
\text { Support }\end{array}$} & B5 & Share ideas or advice. & 3.89 & 1.261 & \\
\hline & B6 & Understand my responsibilities toward my family. & 3.85 & 1.346 & \\
\hline & B7 & Helps me to figure out how to solve the problem. & 3.61 & 1.297 & \\
\hline & B8 & Is understanding or sympathetic. & 3.97 & 1.255 & \\
\hline & B9 & Shows supports for my needs as a working parent. & 3.99 & 1.332 & .923 \\
\hline \multirow[t]{6}{*}{ Family support } & BB1 & Family's attitude is towards you being a worker. & 4.78 & 1.070 & \\
\hline & BB2 & Emotional support provided by your family for your work & 4.64 & 1.127 & \\
\hline & BB3 & Family feels about your commitment to your work. & 4.64 & 1.065 & \\
\hline & BB4 & Feedback from your family about your work. & 4.31 & 1.151 & \\
\hline & BB5 & Family help to do things to make your work life easier. & 4.42 & 1.191 & \\
\hline & BB6 & Family willing to listen to your personal problems. & 4.58 & 1.240 & \\
\hline \multirow{7}{*}{$\begin{array}{l}\text { Family to Work } \\
\text { Enrichment }\end{array}$} & & Involvement in family..... and be a better worker & & & \\
\hline & D3 & Helps to acquire skills & 4.97 & .778 & .924 \\
\hline & D5 & Makes me feel happy & 5.09 & .693 & \\
\hline & D6 & Encourages me to use my work time in a focused manner & 5.03 & .745 & \\
\hline & D7 & Makes me cheerful & 5.06 & .697 & \\
\hline & D8 & Helps me expand my knowledge of new things & 5.02 & .731 & \\
\hline & D9 & Causes me to be more focused at work & 4.99 & .758 & \\
\hline \multirow{5}{*}{$\begin{array}{l}\text { Work to Family } \\
\text { Enrichment }\end{array}$} & & Involvement in work..... and be a better family member & & & \\
\hline & D12 & Helps me to gain knowledge & 5.05 & .718 & .899 \\
\hline & D13 & Helps me feel personally fulfilled & 5.02 & .750 & \\
\hline & D14 & Helps me acquire skills & 5.04 & .713 & \\
\hline & D16 & Makes me cheerful & 5.03 & .703 & \\
\hline \multirow{4}{*}{$\begin{array}{l}\text { Family } \\
\text { Satisfaction }\end{array}$} & Ee1 & Most days I am enthusiastic about my family life & 4.81 & 1.022 & .792 \\
\hline & Ee2 & I feel fairly well satisfied with my family life. & 5.01 & .853 & \\
\hline & Ee3 & I find real enjoyment in my family life. & 5.02 & .822 & \\
\hline & Ee4 & I find my family life better than average person does. & 5.09 & .900 & \\
\hline \multirow[t]{2}{*}{ Job Satisfaction } & Ej6 & Generally speaking, I am very happy with my work. & 4.94 & .925 & .687 \\
\hline & Ej7 & I am generally satisfied with the kind of work I do in my job. & 4.91 & .917 & \\
\hline \multirow{8}{*}{$\begin{array}{l}\text { Well Being } \\
\text { Satisfaction }\end{array}$} & F1 & Interesting & 5.04 & .702 & .912 \\
\hline & F2 & Enjoyable & 5.05 & .701 & \\
\hline & F3 & Worthwhile & 5.17 & .626 & \\
\hline & F4 & Friendly & 5.10 & .699 & \\
\hline & F5 & Full & 4.81 & .817 & \\
\hline & F6 & Helpful & 5.16 & .702 & \\
\hline & F7 & Rewarding & 5.00 & .664 & \\
\hline & F8 & Bring out the best in me & 5.12 & .672 & \\
\hline
\end{tabular}

The second measurement model (Figure 3) comprised of two correlated constructs of work-family enrichment (family-to-work enrichment and work-to-family enrichment). Each of these constructs was measured by more than three items and each item was assumed to load only on its respective dimension. The two factors, namely the family-to-work enrichment and work-to-family enrichment were expected to load on the work-family enrichment.

Using the maximum likelihood estimation procedure of the confirmatory factor analysis, the validity of this measurement model was tested first. However the results did not fit well with the data. The chi-square $=1420.258$ with 134 degrees of freedom was statistically significant at $\mathrm{p}>0.01$ and the overall goodness-of-fit indices was not acceptable (normed chi-square $=10.599, \mathrm{p}$-value $=.000, \mathrm{CFI}=.881$, and RMSEA 0.118). Thus, the initial measurement model is called for modifications in accordance to high modification index on AMOS 18 output. After modification, the revised 
measurement model has a reasonable fit (chi-square $=167.474$, $\mathrm{df}=34$, normed chi-square $=4.926$, $\mathrm{p}$-value $=.000, \mathrm{CFI}=.975$, $\mathrm{NFI}=.969$, and RMSEA 0.76 . In fact, all indicators falling on its posited underlying factor were statistically significant with all critical ratios (t-values) were above \pm 1.96 at 0.05 level respectively. In other words, the measurement of work-family enrichment did generate the observed covariance matrix; there was no evidence that the measurement model is incorrect. In addition, the direction and magnitude of factor loadings were substantial and statistically significant, and the model was free from offending estimates.

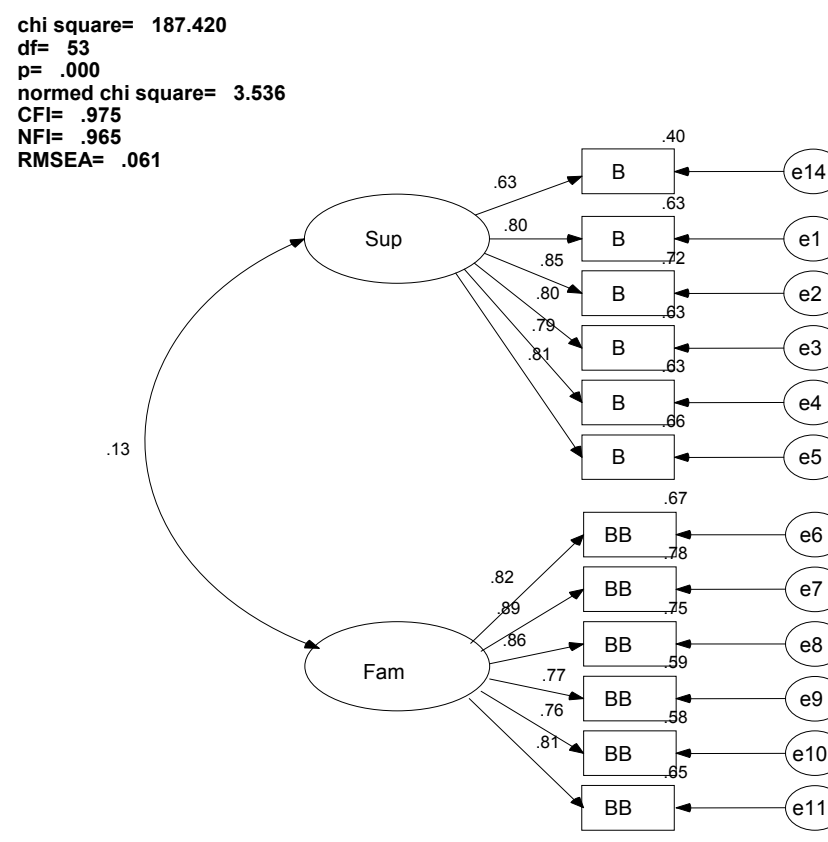

Fig. 2.Measurement Model of Social Support

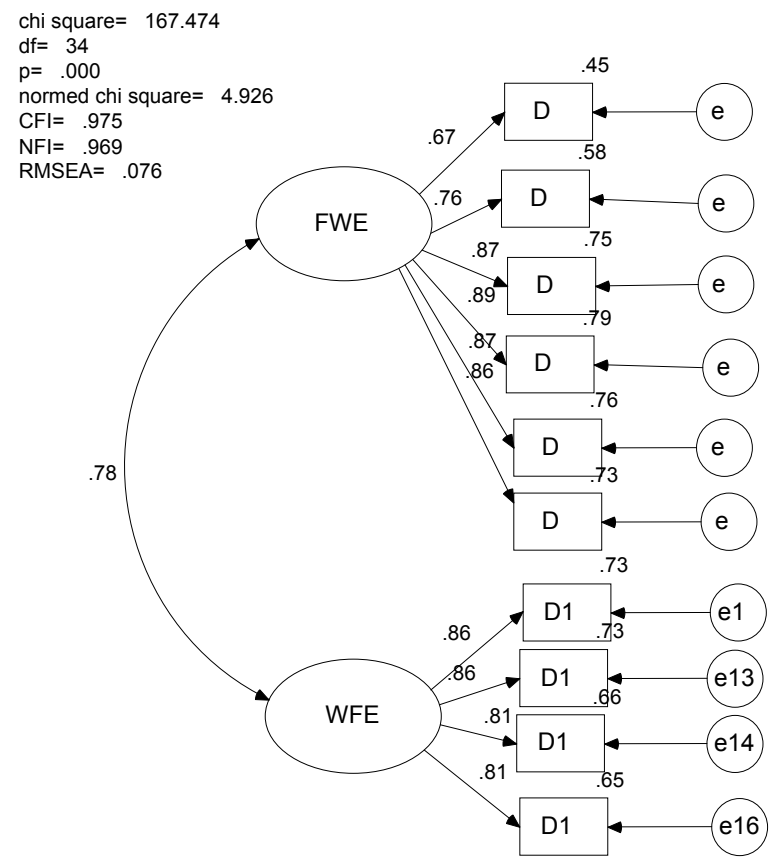

Fig. 3. Measurement Model of Work-Family Enrichment
The third measurement model (Figure 4) comprised of three correlated constructs of life satisfaction (family satisfaction, job satisfaction and well-being satisfaction). Each of these constructs was measured by more than three items, except for job satisfaction (2 items) and each item was assumed to load only on its respective dimension. The three factors, namely the family satisfaction, job satisfaction and well-being satisfaction were expected to load on the social support.

Using the maximum likelihood estimation procedure of the confirmatory factor analysis, the validity of this measurement model was tested first. The results indicated that all indicators falling on its posited underlying factor were statistically significant with all critical ratios (t-values) were above \pm 1.96 at 0.05 level respectively. The overall fit of the model was adequate, the relative Chi-square $=4.76$; RMSEA $=.074$, $\mathrm{NFI}=.930$ and $\mathrm{CFI}=.943$. In other words, the measurement of life satisfaction did generate the observed covariance matrix; there was no evidence that the measurement model is incorrect. In addition, the direction and magnitude of factor loadings were substantial and statistically significant, and the model was free from offending estimates. Notably, the results of each measurement model in this study provided evidence of convergent and divergent validity, thus, these are supporting evidence for construct validity of the model. According to Mueller and Hancock [24], the well fitting of the measurement model establish a possibility of a fitting structural model.

Next, the results of the full fledge SEM (Figure 5), which used AMOS data-fitting program, supported the hypothesized relationships. Specifically, the maximum likelihood estimation of the model yielded the several noteworthy results, which collectively supports the adequacy of the model. The chi-square test of overall model fit resulted with a statistically significant discrepancy between the model and the data $\left(\chi^{2}=1640.254, \mathrm{p}=.000 ; \mathrm{CMIN} / \mathrm{df}=2.966\right)$, however, the other overall fit statistics (RMSEA = .050; $\mathrm{NFI}=.902 ; \mathrm{CFI}=$.932) satisfied their respective thresholds deemed important in a good fitting model. The analysis also produced statistically significant path coefficients, implying the following causal links:

i) social support positively related to life satisfaction of employee

ii) social support positively related to work-family enrichment

iii) work-family enrichment partially mediated the relationship between social support and life satisfaction,

iv) social support however, exerted substantial direct effect on life satisfaction of employee.

In addition the model was free from offending estimates and the directions of the estimates were theoretically justifiable. Finally, the parameter estimates were statistically significant at .05 level, and were of practical importance, since each standardized structural coefficient was larger than 0.2 . 


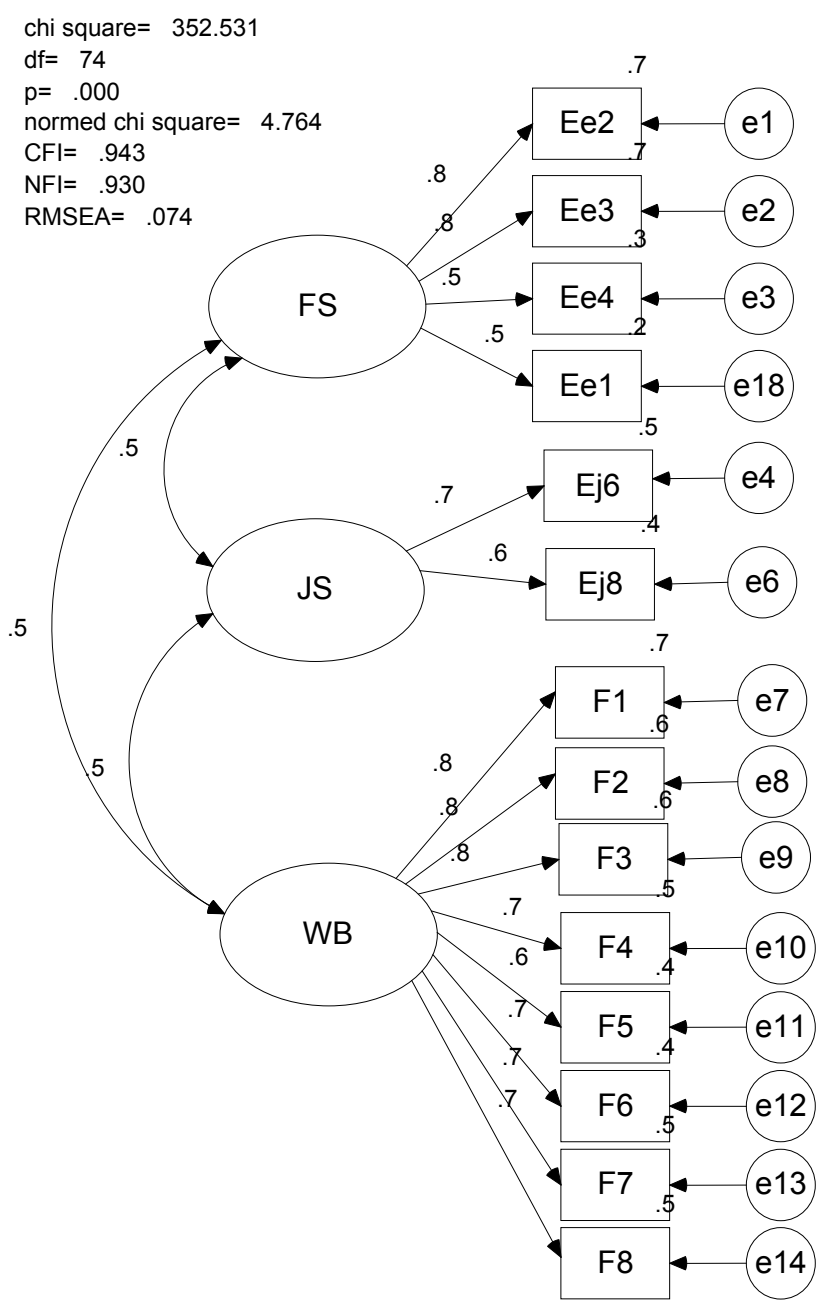

Fig. 4.Measurement Model of Life Satisfaction

\section{DISCUSSIONS AND CONCLUSIONS}

The findings of the present study have expanded the existing body of knowledge on work-family enrichment in several ways. First, the results substantiated the psychometric properties of the measure of social-support, work-family enrichment and satisfaction. The measure seemed sufficient to represent each of the sub-constructs. Second, the data indicated that social support is directly influenced and has significant effect on life satisfaction outcomes such as on well-being, family and job. The result is congruent with the earlier studies on social support [10]-[14], which found that social support has a strong relationship with satisfaction outcomes in enhancing the physical and mental health of a person, as well as increasing family and job satisfaction. Third, the result provides empirical support for a positive relationship between social support and work-family enrichment. As Greenhause and Powell (6) suggested, resources derived from either work or family role help in promoting work-family enrichment. The result is also similar to Hennessey's finding [17] that a person with a higher level of work-family enrichment will probably experience higher levels of support from their friends, family and co-workers. Fourth, the present study provides indications that an individual with higher levels of work-family enrichment are more likely to experience higher level of satisfaction towards wellbeing, job and family. This finding is consistent with the findings of previous studies [17] and assumptions [18] which suggest that increased levels of work and family enrichment may be related to greater satisfaction particularly on job and family matters.

However, this study has several limitations and requires further examination and additional research. First, this study has focused on married nurses with experiences in public health care service. Further research is needed to compare married nurses from public and private healthcare organizations for more rigorous result. Second, since this study only considered married nurses, it is unclear whether the analytical results can be generalized to unmarried nurses, male nurses and other profit-oriented sectors. Finally, the sample of this study was collected in Malaysia, generalizability to other countries might be limited due to cultural differences in managing work-family issues related to social support, work-family enrichment and satisfaction.

Fig. 5. Result of structural model

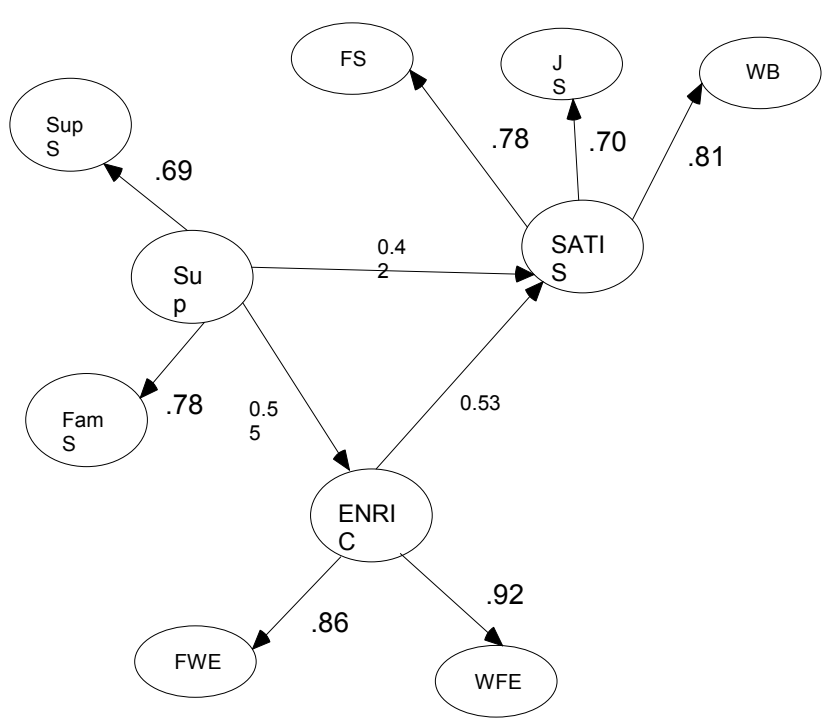

Notes

Sup= Support

SupS= Supervisor Support

FamS $=$ Family Support

ENRICH= Work-Family Enrichment

FWE = Family-to-Work Enrichment

WFE $=$ Work-to-Family Enrichment

SATIS= Satisfaction

FS=Family Satisfaction

JS=Job Satisfaction

WB= Well-Being Satisfaction

\section{REFERENCES}

[1] Andrews, F., \& Withey, S. (1976). Social Indicators of Well-Being. New York: Plenum Press.

[2] Campbell, A., Converse, P.E., \& Rodgers, W.L (1976). The Quality of American Life. Gray. Modern Differential Geometry. CRE Press, 1998.

[3] Kossek, E. \& Ozeki,C. (1998). Work-Family Conflict, Policies and The Job-Life Satisfaction Relationship: A Review and Directions for Organizational Behavior-Human Resources Research. Journal of Applied Psychology, 83, 139-149.

[4] Rothbard, Nancy.P \& Dumas, Tracy L. (2006). Research Perspectives: Managing the Work-Home Interface. In Jones, Fiona, Burke, Ronald J and Westman, Mina (Ed.) Work-Life Balance: A Psychological Perspective. Psychology Press, New York. 
[5] Nooraini Mohd Noor. (2006). Work, Family and Women's Well-Being in Malaysia: Striving for a Balance. Research Centre, International Islamic Universiti Malaysia.

[6] Greenhaus, J.H. \& Powell, G.N. (2006). When Work and Family are Allies: A Theory of Work-Family Enrichment. Academy of Management Review, 31(1),72-92.

[7] Barnett, R. C. (1998). Toward A Review and Reconceptualization of the Work/Family Literature. Genetic, Social and General Psychology Monograph, 12(2), 125-158.

[8] Greenhaus, J.H., \& Parasuraman, S. (1999). Research on Work, Family, and Gender: Current Status and Future Direction. In G.N. Powell (Ed.), Handbook of Gender and Work (pp.391-412), Newbury Park: Sage.

[9] Frone, M. R. (2003). Work-Family Balance. In J.C. Quick and L.E. Tetrick (Eds). Handbook of Occupational Health Psychology. Washington, D.C: American Psychological Association.

[10] Erera, P. (1992). Social Support under Conditions of Organizational Ambiguity. Human Relations, 45(3), 247-264

[11] Kirchmeyer, S. L. \& Lin, T. R. (1987). Social Support: Its Relationship to Observed Communication with Peers and Superiors. Academy of Management Journal, 30(1), 138-151.

[12] Shumaker, S. A. \& Brownell, A. (1984). Towards a Theory of Social Support: Closing Conceptual Gaps. Journal of Social Issues, 40(4), 11-36.

[13] Westman, M. \& Etzion, D. (1995). Crossover of Stress, Strain and Resources From One Spouse to Another. Journal of Organizational Behavior, 16, 169-181.

[14] Izhairi, Ismail. (2004). The Effect of work and Non-Work Variables on Interole Conflict and Quality of Life. Unpublished Doctoral Thesis, Universiti Putra Malaysia, Kuala Lumpur.

[15] Gelsema, T. I., Van der Doef, H.V., Naes, S., Janssen, N., Akerboom, S., \& Verhoeven, C. (2006). A longitudinal studylongitudinal study.
[16] Click the link for more information. of job stress in the nursing profession: Causes and consequences. Journal of Nursing Management, 14, 289-299.

[17] Jeaw-Mei Chen and Phyllis Lan Lin (1992). Daily life demands, social support, life satisfaction and health of working women and housewives. In proceedings of the National Science Council ROC Part C: Humanities and Social Sciences, 1992, Vol.2, No.1, 119-127.

[18] Hennessy, K.D. (2007). Work-Family Balance: An Exploration of Conflict and Enrichment for Women in a Traditional Occupation. Proquest Dissertation, AAT 3277409. University of Maryland.

[19] Grzywacs, J.G. (2000). Work-Family Spillover and Health During Midlife: Is Managing Conflict Everything? American Journal of Health Promotion, 14(4), 236-243.

[20] Sarason, I. G., Sarason, B. R., Shearin, E. N., \& Pierce, G.R. (1987). A Brief Measure of Social Support: Practical and Theoretical Implications. Journal of Social and Personal Relationships, 4, 497-510.

[21] Carlson, D. R., Kacmar, K.M., Wayne, J. H., \& Grzywacz, J.G. (2006) Measuring the Positive Side of the Work-Family Interface: Development and Validation of a Work-Family Enrichment Scale. Journal of Vocational Behavior, 68, 131-164.

[22] Brayfield, A. H., \& Rothe, H. F. (1951). An Index of Job Satisfaction. Journal of Applied Psychology, 35, 307-311.

[23] Hackman, J. R., \& Oldham, G. R. (1975). Development of the Job Diagnostic Survey. Journal of Applied Psychology, 60, 159-170.

[24] Quinn, R.P. \& Staines, G.L (1979). The 1977 Quality of Employment Survey. In Thomas, L.T. \& Ganster, D. C. (1995). Impact of Family-Supportive Work Variables on Work-Family Conflict and Strain: A Control Perspective. Journal of Applied Psychology, 80 (1), 6-15.

[25] Mueller, R.O. \& Hancock, GR. (2008). Best Practices in Structural Equation Modeling in J.W. Osborne (ed). Best practices in Quantitative Methods. London: Sage Publications. 